\title{
MUSEÍSMO PEDAGÓGICO, CONTEXTO Y CIUDADANÍA
}

\section{Pedagogical museology, context and citizenship}

\author{
José María Hernández Díaz \\ Universidad de Salamanca \\ Correo-e: jmhd@usal.es
}

Recepción: I2 de septiembre de 2016

Envío a informantes: is de septiembre de 2016

Aceptación definitiva: 20 de octubre de 2016

Resumen: En este trabajo nos preguntamos por el sentido social del museo dedicado a la educación, de los muchos museos pedagógicos que entre nosotros han aflorado por doquier en las últimas décadas, con más y menos fortuna. Un museo pedagógico debe desempeñar una función de apoyo al investigador en historia de la educación, pero sin dejar de lado la tarea educativa de los miembros de la comunidad, sea cual fuera su edad y formación. El museo pedagógico debe concebirse como una institución educativa abierta al disfrute de toda la comunidad, y a su servicio social, incluso económico. Más allá de las modas culturales y coyunturas científicas o políticas, y con independencia de las modalidades de museos pedagógicos que podemos identificar cerca de nosotros, conviene prestar atención al valor social y comunitario que posee el recurso patrimonial que representa un museo pedagógico.

Palabras clave: Museo pedagógico; desarrollo cultural y comunitario; ciudad educadora.

AвSTRACT: In this paper, we ask ourselves about the social sense of the museum dedicated to education, about the many pedagogical museums that have appeared among us in the last decades, with more and less fortune. A pedagogical museum should play a role in supporting the researcher in the history of education, but without neglecting the educational task of the members of the community, regardless of age and training. The pedagogical museum should be conceived as an educational institution open to the enjoyment of the whole community, and to its social, even economic, service. Beyond the cultural fashions and scientific or political conjunctures, and regardless of the pedagogical museum modalities that we can identify near us, attention should be paid to the social and community value of the patrimonial resource represented by a pedagogical museum.

KEY WORDs: Educational museum; cultural and community development; educating city. 


\section{Introducción}

$\mathrm{L}$

A INCORPORACIÓN DEL MÉTODO ETNOGRÁFICO a la investigación en educación, en particular al ámbito histórico educativo, y la llamada etnografía educativa han despertado en el seno de nuestra comunidad científica de historiadores de la educación un creciente interés lector e investigador por este campo, y han generado en los estudios de historia de la educación nuevas formas de análisis y hermenéutica, complementarias de otras ya exploradas o insertas en ese proceso.

Pero si nos referimos de manera concreta al movimiento del museísmo pedagógico, la visibilidad del concepto que acoge este sintagma, y el tipo, diversidad y calidad de prácticas educativas y de expresiones institucionales pedagógicas y culturales que representa, nos conduce a la percepción de una imagen sorprendente, la de un movimiento que en España apenas balbuceaba solo dos décadas atrás, y hoy se ha erigido en un campo atractivo e imprescindible en nuestra historiografía. Algunos de los trabajos de J. Ruiz Berrio (2006, 2010), V. Peña Saavedra (2003, 2004.), J. M. Hernández Díaz (1993, I997, 2000, 2003a, 2003b, 2009, 20I0, 20II), P. L. Moreno (2010), V. Juan Borroy (2008), C. Agulló (20II), y las actas de los coloquios o jornadas organizadas por la creada Sociedad Española para el Estudio del Patrimonio Histórico Educativo (nacida oficialmente en 2004 y promovida de forma incansable y certera por Julio Ruiz Berrio), entre otros muchos textos, monografías y artículos de revistas, nos permiten entrar de lleno en un campo vasto, de amplia y densa información, pero necesario para comprender en directo la rápida evolución que ha vivido el tema del museísmo pedagógico en España, así como también en otros países de Europa, Asia y América Latina y del Norte.

El nuevo museísmo pedagógico viene caminando muy rápido, desarrollando varias direcciones y ámbitos educativos y se sitúa dentro, pero también más allá, de la cultura escolar explícita. El museo de la educación, el museo pedagógico ha comenzado a erigirse en una oportunidad para la mirada de un espectador que no solo es experto en educación, o en historia de la educación en concreto, sino que también es un ciudadano normal, con cierto grado de cultura, y con un creciente nivel y capacidad de explorar y apropiarse de una lectura con sentido emotivo y estético hacia un objeto y ambiente de significación pedagógica, del pasado y de la actualidad.

Un museo en general, y un museo pedagógico en concreto, que no suscite sensibilidad, emoción, sugerencias interpretativas, sensaciones nuevas, placer intelectual y estético que invite a una nueva mirada al visitante, que no cale en el corazón y las emociones de quienes acuden no merecería la condición de ser reconocido como museo. Por ello, el museo debe ser concebido como un espacio de sentido (Zunzunegui, I990), y, si adopta el adjetivo de pedagógico, el museo debe lograr alcanzar sentido educativo, formativo para quien se aproxime a su disfrute. Así se puede situar en la raíz de lo que desde el origen de los museos resulta decisivo, como es la capacidad de suscitar creatividad, preguntas, como espacio de originalidad, de búsqueda de sentido, de invitación a la hermenéutica. De esa forma se aproxima a lo que en su origen fuera el primer Museo de Alejandría, el lugar de las musas en sentido literal original (mouseion), el lugar por excelencia en la Antigüedad para el cultivo de la sensibilidad, el espacio adecuado para la inspiración del saber y la oportunidad visible para la creación original en todos los campos del saber y la ciencia.

En este breve trabajo nos interesa la pregunta por el sentido social del museo dedicado a la educación, de los muchos museos pedagógicos que han aflorado como 
hongos por doquier, con más y menos fortuna. Con el debido respeto a algunos colegas, entendemos que un museo pedagógico debe desempeñar una función de apoyo al investigador en historia de la educación, pero sin dejar de atender a la tarea educativa de los miembros de la comunidad, sea cual fuera su edad y formación. Concebir un museo pedagógico como espacio recóndito de disfrute de una minoría selecta de académicos e investigadores es limitar de manera necia y sesgada la dimensión central de una institución educativa que debiera abrirse al disfrute de toda la comunidad, aunque fuera de diferente forma y vías de acceso.

\section{El museo pedagógico en su marco de referencia}

Un museo pedagógico tiene que concebirse, e interpretarse, en su contexto de referencia socioeducativa, en el que nace, con sus apoyos institucionales y de personas, para comprender mejor sus fortalezas y debilidades, y para buscar siempre posibles alianzas, mejoras y beneficios de visitantes y miembros de la comunidad. De ahí que merezca tantas dudas un museo pedagógico concebido desde el gabinete de una sola persona en exclusiva, más aún solo desde el gabinete académico, porque ello significa desaprovechar la riqueza y oportunidad de la construcción comunitaria de un proyecto formativo en el que puedan implicarse diferentes colectivos e instituciones.

Un museo pedagógico descontextualizado, concebido a manera de colección privada, construido de forma artificiosa y «científica» (en el sentido de adorno superficial que también puede atribuirse a este término) desaprovecha una categoría decisiva en el mundo de la mirada pedagógica colectiva. Por tanto, huyamos del secuestro de lo pedagógico en forma de museo, de un museo pedagógico descontextualizado, porque sin duda alguna va a caer en la fosa profunda del silencio de la comunidad social y científica, aunque estas colecciones de objetos puedan soportar impasibles la marcha de los años recluidas en espacios ad hoc que no son los de su significado natural.

El panorama actual del museísmo pedagógico en España, y en el mundo (países de Europa y América y más recientemente Asia se va incorporando), es lo suficientemente amplio en su número y diverso en sus formatos como para no establecer clasificaciones rígidas ni simplistas, más propias del tradicional escolasticismo, y mucho menos exhaustivas en sus pretensiones. A pesar de todo podemos avanzar alguna aproximación interpretativa, con la intención principal de que nos sirva de ayuda en nuestra reflexión y propuesta posterior.

I.I. Si atendemos a su ubicación física podemos identificar museos pedagógicos procedentes de anteriores usos industriales e instalados in situ dentro de la antigua fábrica, molino de agua, taller de artesanía, buscando despertar la sensibilidad y comprensión hacia la formación de los trabajadores y el desempeño profesional de los mismos, así como a sus condiciones laborales y de vida. Así podremos disfrutar de preciosas expresiones de museos del hierro, de la industria textil, de la piedra, de la minería, de la sal, a caballo entre la antropología, lo etnográfico y lo educativo.

Si computamos la ubicación de buena parte de los museos pedagógicos (así llamados alegremente y con ligereza entre nosotros en muchas ocasiones) éstos se encuentran situados en localidades rurales. Y razones explicativas no faltan. Bien porque en ámbitos rurales se han podido conservar mejor que en la ciudad diferentes 
utensilios, objetos, materiales escolares, edificios, tradiciones orales, musicales, teatrales. Bien porque el tránsito de una sociedad rural a otra de tipo industrial se ha producido entre nosotros hace solo una generación, y por ello se mantiene viva la memoria del origen, y el sentido emotivo de muchas tradiciones y objetos educativos, dentro y fuera de la escuela. Por todo ello, la búsqueda de señas de identidad de muchos estudiosos de la educación va a proyectarse en la vuelta al campo, desde donde emergen expresiones culturales y objetos materiales de referencia con significado cultural y formativo. Es fácil explicar que numerosas comunidades rurales que ya no disponen de escuela primaria en activo, porque simplemente no nacen ni allí viven niños, dediquen al antiguo espacio escolar a un llamado museo pedagógico que suele reducirse a la muestra de la sala de clase, en el mejor de los casos con el mobiliario del aula, algunos libros escolares de la última época de vida de la escuela y diferentes elementos ornamentales y útiles pedagógicos. Muchos de estos pequeños museos pedagógicos son gestionados de manera no profesional, pero cuentan con el apoyo, la audacia y el compromiso de buena parte de la pequeña comunidad rural, porque es el museo de todos, del pueblo, de la aldea.

Los museos pedagógicos situados en la ciudad suelen ser resultado de una decisión administrativa, local, autonómica o de un patronato o iniciativa privada. En ellos se pueden combinar elementos escolares y educativos de otro signo, con frecuencia destinados a satisfacer la curiosidad de un visitante anónimo e indiferenciado, aunque también interesen a los posibles historiadores de la educación. Suelen ser propicios para visitas de grupos escolares y estudiantes universitarios, grupos de personas mayores y turismo organizado, y cumplen una más que interesante función formativa y educadora, además de proteger mejor el patrimonio histórico educativo al adquirir, conservar y a veces restaurar objetos y elementos de la historia educativa colectiva que lo precisen.

Aunque los museos pedagógicos instalados en algunas universidades, a manera de laboratorios de investigación, o como espacios complementarios y formativos del ámbito de la historia de la educación, dirigidos a estudiantes de magisterio y de ciencias de la educación, obviamente pertenecen en lo físico a la ciudad, sin embargo, no suelen ofrecer la oportunidad de la visita y la apertura a la comunidad de proximidad y a la sociedad en general. El ejemplo que estudiamos hace algunos años en el Museo Pedagógico de Montevideo es solo una pequeña muestra de lo sugerido ahora (Hernández Díaz, 2009).

De enorme interés entre nosotros es el movimiento de los museos y colecciones de los institutos históricos de segunda enseñanza existentes en España (López-Ocón et al., 2012), así como de las colecciones de colegios históricos de congregaciones religiosas y seminarios diocesanos. Estas instituciones de la segunda enseñanza, oficial o privada, han desempeñado desde mediados del siglo xIX una función formativa decisiva para las élites, y en lo que afecta a la materialidad de los recursos didácticos han dispuesto de mayores recursos y oportunidades de adquirir novedades, a veces importadas de países escolarmente más avanzados, sobre todo de Francia, Alemania e Inglaterra. Varios institutos, colegios privados y seminarios diocesanos han sabido y podido conservar colecciones de materiales didácticos que han comenzado a ser expuestos y estudiados con criterios museísticos actualizados, y por fortuna muchos en su marco original de uso y ubicación en el centro educativo.

Territorio diferente son las colecciones privadas de útiles escolares o de la infancia (de juguetes, sobre todo), a veces muy valiosas, que han sido seleccionadas con primor 
y gusto estético durante años por su dueño. Estas colecciones con frecuencia han sido costeadas sin reparos, y se muestran en escasas ocasiones al público, pero desempeñan una función afirmativa para el prestigio de su propietario entre la élite que la visita, como expresión de lujo económico o gusto intelectual, o para disfrute muy personal y reservado del artífice de la colección construida a lo largo de una vida con esfuerzo, detalle y dinero. Es muy probable que, como nosotros, el lector conozca varios casos de los mencionados, y que no vemos oportuno citar nominalmente aquí. Son a veces antiguos profesionales de la inspección educativa, quienes a veces han reservado lugares concretos de su propia vivienda para cobijar los materiales escolares de la colección. Son en ocasiones profesionales liberales y solventes (farmacéuticos, médicos, abogados, conocemos varios) que se han entusiasmado con los costosos juguetes o artefactos pedagógicos de una etapa concreta de la historia. Es el camino del afecto y del corazón, de la emoción personal, también puede ser de la nostalgia, que debe ser muy respetado, y que con el tiempo cuaja a veces en la organización de un pequeño museo pedagógico o en la donación a otro museo etnográfico o de una institución educativa (Hernández Díaz, 1997).

Los museos universitarios son otra tipología de museo pedagógico muy diferente a las que venimos contemplando, aunque no menos real y expresivo de una institución formativa superior (García Fernández, 20I5). Dan cuenta del patrimonio histórico, espacial, bibliotecario o de materiales pedagógicos en desuso, que resultan imprescindibles para comprender los procesos formativos y de investigación que se han desarrollado en la universidad en las últimas generaciones. Es indudable que algunas universidades poseen un patrimonio histórico educativo extraordinario, bien sea en antiguas Facultades, Escuelas Normales, Archivos y salas especiales.

A partir de la llegada de Internet existe otra modalidad de colecciones llamadas museos virtuales (Collelldemont Pujadas, 20Io), de indudable interés informativo y sustitutivo de lo presencial, cuando no queda otra opción para conocer una exposición o colección, por razones de dificultad en el desplazamiento u otras de orden económico, o para procurar dar mayor visibilidad a un producto museístico. En sentido riguroso el visitante de una web de museo pedagógico, y existen muchas ya en el mundo, se adentra en un ámbito informativo y curioso, pero consciente de la ausencia que la originalidad de los objetos y materiales transmite de forma directa, y por ello no tan fácil de transmitir emociones en un encuentro personal entre el sujeto y el objeto de componente o trazo pedagógico. El museo virtual es una realidad de nuestro tiempo, que hemos de comprender y utilizar, aun con la conciencia de sus límites, pues carece de marco de referencia original, y con el riesgo evidente de descontextualización.

I.2. Analizando con algo más de precisión y diseccionando con bisturí analítico el formato y tipología que engloba la denominación genérica de museo pedagógico, bien pueden diferenciarse algunos modelos de museo pedagógico, tanto por la tipología organizativa que ofrece como por la temática de materiales que acoge.

Así, podemos encontrarnos varios de ellos dedicados en exclusiva a la historia del juguete, incluso a la historia de la muñeca (el Pupenmuseum de la ciudad de Goslar, en Alemania, es formidable), o museos de época que ofrecen salas concretas destinadas a los juguetes y muñecas de aquel momento. Tales salas de elementos educativos suelen insertarse en expresiones museísticas de corte etnográfico o en colecciones muy selectas que participan de lo que desde la historiografía educativa 
denominamos historia de la infancia, la historia de la familia y de la vida cotidiana. Así, por ejemplo, las salas de la infancia que conservan el Museo Etnográfico de Castilla y León en Zamora o la colección de juguetes y muñecas del Museo de Art Nouveau y Decó de la Casa Lis de Salamanca nos parecen muy representativas de lo que aquí indicamos.

Diferentes museos etnográficos, unos locales, otros provinciales, autonómicos o nacionales, o el equivalente en colecciones privadas de fundaciones y particulares, van incorporando muchos elementos de la cultura educativa, sea en la familia, en la escuela o de la calle y la vida cotidiana, y a veces museos de procedencia religiosa. No son museos pedagógicos en sentido estricto, pero contienen muchos elementos de identidad educativa.

Otra tipología más definida de museo pedagógico es el museo escolar, y más aún el aula museo, aunque los más importantes museos pedagógicos existentes entre nosotros (el de Aragón o el de Galicia, por ejemplo) han ampliado y sobrepasado con creces este concepto tan restrictivo. Es cierto que la mayoría de ellos se ciñen a la cultura escolar y sus manifestaciones materiales, lo que no debe suponer ningún desdén, dada la importancia que el sistema escolar y sus instituciones merecen en la historia cultural, en particular, en la etapa contemporánea. Ahora bien, un museo pedagógico dinámico, y con el nombre de tal, de ninguna manera puede recluirse en el formato de una sala de exposiciones donde solo se muestra una expresión escolar concreta, sin plantearse otras iniciativas culturales que pudieran dinamizarlo y explotar mucho mejor su contenido expositivo de la cultura escolar.

I.3. Una tercera reflexión sobre el tipo de museos pedagógicos nos lleva a puntualizar sobre su adscripción administrativa y procedencia, así como su concepción formativa y científica, que sin duda condiciona cualquier proyecto innovador que se proponga sobre los museos pedagógicos.

Es sabido que, entre nosotros, el conocido como Museo Pedagógico Nacional nace en Madrid en I882, creado y sostenido desde la administración central hasta que finaliza su ciclo en 194I (García del Dujo, 1985). Sigue pautas de otros museos pedagógicos que se iban creando en Europa, organizándose en lo fundamental según el modelo organizativo del nacido en Paris (1878). Nos interesa subrayar que el Museo Pedagógico que dirigen M. B. Cossío y más tarde Domingo Barnés, desde I882 hasta 1936, ha roto con la concepción tradicional y pasiva para el visitante, elitista y selecta que se había atribuido a los museos. Por el contrario, es el lugar de la invención y la formación, y en ciertas salas de la presentación de novedades y del ayer pedagógico, de la investigación y la difusión. Por ello se erige en pauta museística del camino que han de seguir estas instituciones orientadas al campo de la educación y la pedagogía.

Un museo pedagógico debe huir del almacenamiento, de la pura acumulación y recogida de objetos escolares o educativos, para concebirse como un espacio para la interpretación y disfrute de elementos con significación formativa y estética. De ahí que la función didáctica y hermenéutica deba ser atendida con tanta intensidad como la ordenación, protección o la lógica expositiva de los materiales. Se impone una pedagogía museística, también para los museos pedagógicos que conocemos. En este punto nos parece paradigmática la organización expositiva y científica del museo pedagógico de Rouen, en Francia, continuador del histórico de París ya mencionado, 
donde se conceden espacios diferenciados a la consulta de los especialistas, pero también al disfrute de los ciudadanos, y al uso didáctico de los profesores con sus estudiantes, de diferentes edades y niveles.

Con independencia de qué tipo de administración pública (municipal, autonómica, Nacional), organismo, fundación, empresa o iniciativa privada promueva la creación y mantenimiento activo de un museo pedagógico, debe quedar garantizada la calidad técnica del espacio expositivo y de investigación, la seguridad para los materiales y lo invisible de cada museo, pero tan imprescindible, como es la tarea oscura de estudio, organización y restauración de materiales.

Es preciso evitar el riesgo del silencio y del olvido que pueda cernirse sobre un museo pedagógico, de la clase y administración que fuere, dándole vida y dinamismo. Y para ello conviene evitar también el riesgo de su secuestro si se produce una construcción artificiosa, «científica», descontextualizada del museo pedagógico. Ahí entra en juego la dimensión social del mismo.

\section{Museísmo pedagógico y desarrollo sociocomunitario}

Los objetos de significado educativo que se exponen en los museos etnográficos y pedagógicos, y los mismos establecimientos museísticos de esta clase, dejan de ser propiamente elementos materiales indiferenciados y se van a convertir en representación de la identidad de los humanos que los han creado y utilizado en su momento por alguna motivación estética, comunicativa o formativa. Esos objetos y materiales seleccionados se erigen en imagen y retrato de nuestra personalidad colectiva educativa e histórica, a veces como expresión profunda de una persona o grupo concreto con identidad. Pero seguramente precisan verse avalados y acompañados de un sentido hermenéutico que permita interpretar mucho mejor la validez de lo expuesto y representado en los museos pedagógicos.

En el museismo pedagógico nunca pueden dejarse a un lado los criterios técnicos, expositivos y estéticos, que han de ir orientados al aprendizaje y disfrute del visitante, con independencia de la formación cultural y estética que posea el individuo, el grupo que visita y el conjunto de la comunidad donde se inserta el museo pedagógico.

$\mathrm{Va}$ existiendo acuerdo entre antropólogos, directores de museos, historiadores del arte, cultivadores profesionales y amateurs del patrimonio artístico y cultural en torno a las principales funciones que han de desempeñar museos, establecimientos expositivos, actuaciones permanentes u ocasionales sobre cualquier aspecto del patrimonio histórico, programas de acción sobre el patrimonio artístico y cultural (Grassi, 2015; Díaz González, 2006: 76). Así, parece que son funciones socioeducativas de todo museo, y de un museo pedagógico en concreto, que hoy no se cuestionan y que compartimos, las de servir para el estudio científico y aprovechamiento estético y cultural por parte de cualquier miembro de la sociedad; preservar del olvido o del deterioro el bagaje histórico y cultural de los materiales educativos rescatados o encontrados; servir de acicate para la creatividad del visitante u observador; constituir una base sobre la que el individuo pueda integrarse, si lo desea, en la sociedad y en la comunidad de referencia que le acoge.

Sugerimos para nuestro caso de interés en este texto, el patrimonio histórico educativo, que se tome en consideración esa propuesta orientativa sobre la dimensión 
social y científica de los museos pedagógicos y espacios expositivos equivalentes, por circunstanciales que sean sus actuaciones.

2.I. En primer lugar, el museo pedagógico logrará legitimidad social y científica si se concibe al servicio de cualquier miembro de la comunidad próxima y del conjunto de la sociedad, para facilitar su estudio, o para que le aproveche culturalmente o en algún aspecto de su formación.

Lo que significa que una institución cultural y formativa como el museo pedagógico ha de contemplar una lógica de pertenencia al ámbito de lo público (más allá de su propiedad jurídica), para que pueda estar garantizado el acceso y disfrute de todos los ciudadanos al establecimiento cultural que mencionamos.

El acceso físico al museo pedagógico quedará resuelto para todos los usuarios posibles, de todas las edades, incluidas aquellas personas que sufren discapacidad de movilidad y otras posibles limitaciones físicas. Por tanto, accesibilidad plena, y en la medida que sea posible, de forma progresiva, han de proporcionarse instrumentos mediadores del lenguaje escrito y oral adaptado a las personas con discapacidad visual o auditiva. Acuerdos y convenios con organismos como la ONCE ya se encuentran funcionando en algunos museos españoles, aunque no precisamente los pedagógicos que conocemos.

Por supuesto, al museo pedagógico debe facilitarse acceso fácil, gratuito o muy asequible desde el punto de vista económico y adquisitivo, pero también sin restricciones de género, raza, condición social ni confesión religiosa. Y desde luego de edad, porque este recurso patrimonial es de todos, universal, y debe ser útil para el disfrute y la formación de niños y tercera edad, miembros de asociaciones culturales y ciudadanos en general. Lo cual implica, al igual que ocurre en otros espacios y bienes culturales y del patrimonio histórico, que ha de existir un departamento didáctico, una pedagogía del museo, que sea adecuada para que los visitantes, en cualquiera de las situaciones mencionadas, si fuera el caso tengan la oportunidad de una visita mucho más provechosa y perfilada que un simple paseo pasivo y genérico por el museo, aunque sea apoyado por un guía preparado al efecto.

Dentro de un concepto más extenso e integrador del avance cultural de la población donde se ubica e inserta, sea ésta una ciudad o bien una localidad rural, el museo pedagógico de ninguna manera puede dejar de atender a la idea y la práctica de la ciudad educadora, en la que todos sus recursos patrimoniales han de concebirse al servicio de la comunidad, como parte de su riqueza educativa y en consecuencia de la oferta a la ciudadanía. El conocido movimiento de ciudades educadoras, que nace en Barcelona en 1992, y que celebrará próximamente una nueva edición en forma de congreso en la ciudad portuguesa de Guarda, expresa de forma rotunda la inserción del patrimonio cultural y museístico en la oferta activa de la ciudad al servicio de la cultura, en cualquiera de sus manifestaciones, una de ellas es la red de museos existente en la ciudad. El museo pedagógico tiene que erigirse en un espacio de mediación social y cultural de la ciudad, en un recurso pedagógico al servicio de la comunidad, que puede quedar integrado en una red abierta de oportunidades culturales y formativas.

El museo pedagógico debe ser al fin, y por encima de todo, un espacio orientado a la educación y a la formación de los ciudadanos, y también de sus educadores, profesores y formadores, en activo o en camino. Por ello se impone una estrecha 
relación con las instituciones de educación superior responsables de la formación de los especialistas educativos en todas sus expresiones (maestros de educación infantil y primaria, profesores de educación secundaria, pedagogos, educadores sociales y otras expresiones de educadores profesionales). Es obvio que tal relación debe quedar lo más institucionalizada posible para garantizar la continuidad y consolidación de los proyectos formativos teóricos y prácticos.

El museo pedagógico ha de erigirse también en una nueva oportunidad para la construcción de conocimiento pedagógico, histórico educativo en concreto, didáctico o socioeducativo. En consecuencia, además de organizar un departamento interno de investigación dentro del establecimiento, con varias secciones o grupos de investigación si en su caso fuese preciso, el museo debe quedar abierto y accesible a los investigadores. Si nos ceñimos al ámbito histórico educativo, sabemos que el campo de la etnografía escolar y de la infancia, y la historia material de la escuela y la educación, desde la indudable influencia del eco de la Escuela de Annales (con incidencia expresa en la historiografía mundial después de 1945), representan en la comunidad científica de los historiadores de la educación una reconocida novedad desde hace algunos años, formando parte destacada del acervo historiográfico compartido en nuestro presente. Por ello, el museo pedagógico quedará enriquecido con la orientación, la presencia y el apoyo continuado de investigadores en historia de la educación. Y algo semejante podríamos atribuir a la investigación de educadores sociales y didactas.

2.2. En segundo lugar, el museo pedagógico ha de contribuir a preservar de la destrucción y del olvido los objetos, materiales, útiles de la infancia que conformen algún aspecto de la historia educativa personal o colectiva, que es lo que denominamos el patrimonio histórico educativo.

Conservación, protección, vigilancia, restauración son sustantivos imprescindibles para la vida de un museo pedagógico, aunque no siempre sean visibles al espectador o visitante. Por lo tanto, todo museo pedagógico que se precie de tal debe disponer de almacenes ordenados para los materiales recibidos, donados o adquiridos, y un taller de restauración, limpieza, organización y adecuada catalogación técnica de objetos de su patrimonio educativo. Estamos muy mal acostumbrados a designar una colección de materiales escolares o pedagógicos como museo, pero tales útiles, o bien están catalogados y protegidos, o no aparecen bien descritos, a veces no restaurados por especialistas. Todo es consecuencia del débil valor social, económico y científico que por tradición se ha atribuido a los materiales pedagógicos del pasado, considerados muy endebles y poco valiosos en el mercado anticuario y de fuerte fragilidad histórica.

El movimiento de los museos pedagógicos que recorre el mundo en las tres últimas décadas sin duda alguna que va a contribuir a dignificar el valor real del patrimonio histórico educativo, y a impulsar la necesidad de organizar técnicamente con criterio científico los actuales museos pedagógicos, y desde luego los que se vayan a crear en el futuro.

Por el carácter subsidiario que en la historia se ha atribuido a la enseñanza de primeras letras, más tarde escuela primaria, los objetos y materiales propios de la actividad escolar han recibido una atención de segundo grado, cuando no despreciable (léase pizarras, libros, manuales escolares, cuadernos, mobiliario, entre otros), en el mismo rango que se encontraba postergada la profesión de maestro hasta etapas bien recientes de nuestra historia pedagógica. Por fortuna, las últimas décadas representan 
en todo el mundo un cambio de orientación para el valor de uso y de cambio, y sobre todo el valor científico y museístico de muchos de estos materiales.

Algo parecido podemos aplicar a los materiales y vestigios de las prácticas de otras instituciones educativas diferentes a la escuela, que han venido siendo admitidas como de segunda clase (internados, centros de acogida de niños y adolescentes, antiguos reformatorios, casas cuna, centros de educación de analfabetos, centros juveniles, movimientos de juventud, centros de animación sociocultural, clubes de lectura, ateneos culturales, por ejemplo, entre tantos más).

Rescatar del olvido, del desván, del anticuario, o incluso a veces del basurero, los objetos que componen un museo pedagógico es una función muy loable y necesaria, pero no es la única, ni siquiera la más importante. Ésta será, con seguridad, la de darles significado y explicación, porque el material pedagógico, como sugieren diferentes museólogos y etnógrafos (Sachetto, 1985; Stocking, 1986, entre otros), el objeto material propio de la educación y sus instituciones nos informa, sugiere y nos propone significados, explicaciones y nos invita a la hermenéutica de su peso, forma, color, material de que está elaborado o fabricado, función que cumple para la infancia, de su gramática explicativa (Fiorani, 2002). Es preciso entrar en el juego interpretativo de la cultura material de la educación, y por supuesto en la cultura escolar y sus expresiones materiales (Chervel, 1998).

La tarea científica y social de los especialistas en museísmo pedagógico será precisamente la de ofrecer a los ciudadanos, a la comunidad próxima y a todo tipo de visitantes, la presentación y explicación ordenada de los materiales expuestos con la máxima calidad expositiva posible, y desde luego dentro del mejor y deseable sentido estético.

Ello va a exigir disponer de personal cualificado y motivado en el ámbito del museismo pedagógico, para atender las demandas explicativas, para organizar salas permanentes y exposiciones variables o temáticas, para dar sentido y vida real a un museo pedagógico, que debe distar mucho de la pura y fría presentación de objetos y materiales pedagógicos a un visitante indiferenciado.

2.3. El museo pedagógico se concibe como un espacio de sugerencias y emociones, y ha de servir de acicate para la creatividad.

Es bien sabido que el lejano origen de los museos es consecuencia del interés que patricios romanos, reyes y potentados tocados de cierta sensibilidad estética y cultural, príncipes de la Iglesia, aristocracia y alta burguesía más tarde mostraron hacia el consumo y disfrute privado de objetos y espacios bellos y ornamentales (tapices, esculturas, frescos en las paredes y todo tipo de expresiones pictóricas, jardines). A veces el museo nace también como búsqueda y signo de distinción entre sus iguales, primero en sus residencias y palacios, y ya en el contexto de la Ilustración en espacios expositivos y museísticos diferenciados y segregados, que comienzan a abrirse al gran público, o al menos salen del ámbito de lo privado y selecto. En ellos se depositan y exponen colecciones reales, o privadas, que pretenden trasladar al visitante el gusto por la cultura y la estética de formas muy diversas. Desde entonces hasta nuestros días la evolución técnica y organizativa de los museos no ha hecho más que cambiar y mejorar, pero siempre manteniendo la dimensión estética y creativa, emocional, lúdica y placentera de lo expuesto, pensando en una búsqueda personal en el tiempo libre y de ocio constructivo del visitante. 
Aunque el origen de los museos pedagógicos en Occidente, a partir de las Exposiciones Universales del siglo xix, debe situarse en un plano más práctico, orientado hacia la mejora de los métodos pedagógicos, sus instalaciones y materiales de uso, pronto se comprueba la idoneidad de no perder la perspectiva de algunas de sus salas al servicio de la comprensión histórica de la educación y de la motivación de los visitantes, incluso a trasladar al público muchos elementos de carácter emotivo, a veces nostálgico, y siempre de interés cultural y formativo. Por ello, a medida que se ha ido consolidando el ámbito de los museos pedagógicos en todo el mundo, éstos se han ido organizando con criterios técnicos y estéticos equivalentes a otros museos, y desde luego los relacionados con la emoción de la belleza que desprenden algunos de ellos, o el conjunto de una composición armónica (un aula del ayer, por ejemplo).

Con independencia de la hermenéutica de los objetos pedagógicos particulares, tan necesaria en los museos, para huir de lo banal y una visita superficial, el museo pedagógico ha de ser capaz de construir una gramática propia, un itinerario con identidad (o varios), capaz de conducir a visitantes muy heterogéneos en interés, motivación, formación y edad, hacia el mundo de las emociones, al menos a través de ciertos objetos o salas especiales. Una pedagogía del museo no debe concebirse de forma antagónica al disfrute libre y personalizado, pues pueden ser complementarios. Pero si solamente concebimos el museo pedagógico como un aula más, por muy bonita que parezca, y no se permite que emerja el lado de las emociones del ciudadano visitante cuando contacte con los objetos y salas, hemos perdido una buena oportunidad del éxito que ha de lograr el rato que permanece en las salas del establecimiento. Lo cual significa que, a veces, ha de buscarse una mayor interacción para combatir la inevitable pasividad y comodidad en que se sitúa el visitante adulto. Lo ideal pasa, desde luego, por un compromiso más continuado e intenso del ciudadano de una comunidad con su museo, porque llegue a concebirlo como algo propio, más allá de que quede abierto al disfrute de otros ajenos al pueblo, barrio, ciudad.

Una de las circunstancias adversas para un clima emocional y creativo dentro del museo se representa en el turismo de masas o en el almacenamiento de visitantes ante salas u obras de especial atractivo o importancia. Valga mencionar de pasada lo que sucede con la visita masificada a la Capilla Sixtina en el Vaticano, la Galería de los Uffizi en Florencia, o a veces ciertas salas del Museo del Prado o el Reina Sofía, del Bristish Museum o el Louvre, por mencionar algunos bien conocidos. Es evidente que el museo pedagógico dista mucho de tales posibilidades y atractivos para el gran público, pero lo que queremos trasladar, por contraste, es que el museo pedagógico siempre necesita de un margen de soledad o de disfrute personal, o en pequeño grupo, para ganar en sentimiento y disfrute estético, que a veces se combina con la nostalgia.

Bien concebido, explicado, seleccionado, motivador, ilusionante, el museo pedagógico se erige para el visitante en un interlocutor de emociones y aprendizajes, pues toma parte activa en la vida del museo, y de esa forma lo enriquece y da sentido, da calor y elimina distancia y frialdad. Lo que requiere que cada museo pedagógico tenga su identidad, su personalidad.

La vieja tríada platónica del «verum, bonum y bellum», de la verdad, bondad y belleza como ideal formativo, puede quedar bien recogida en el proyecto pedagógico y expositivo de un establecimiento de esta clase, que debe dejar a un lado el posible lastre elitista y de cultura de minorías, para proponer al ciudadano que se acerca al 
museo pedagógico una lectura original, personalizada, satisfactoria y emotiva. Es otra dimensión socioeducativa, sin duda, la que debe contemplarse en su organización.

Y regresando a un comentario precedente, si retomamos la idea original representada en el Museo de Alejandría, paradigma de tantas iniciativas científicas y culturales a lo largo de la historia, el mouseion era el espacio de las musas, de la inspiración, de la creación de conocimiento, de la creatividad y la originalidad. Por tanto, en la medida que procuremos espacios para la inspiración, en este caso pedagógica y cultural, estaremos acercando nuestros museos pedagógicos a aquel viejo ideal alejandrino de creación, belleza, y placer intelectual.

\subsection{El museo pedagógico como factor de socialización y promotor de desarrollo comunitario.}

Una vía de socialización de la cultura es el turismo, además de una fuente de ingresos nada despreciable, afianzada e imprescindible en estos comienzos de siglo XxI, más aún en un país como España con casi 80 millones de visitantes extranjeros al año, y hoy con una movilidad interna extraordinaria por parte de sus ciudadanos. Más allá de otras modalidades de turismo como fenómeno de masas, sea el de playa o el ecológico, el denominado turismo cultural (en el que cabe ubicar el museo pedagógico como elemento patrimonial de cultura) está plenamente afianzado y resulta atractivo al usuario y visitante. No obstante, como piensan destacados especialistas en patrimonio urbano y cultural, es susceptible de cuestionarse en muchos casos el tipo de cultura que representa ese turismo, que en ciertas fechas abarrota un espacio patrimonial destacado, o una exposición, y con ello queda desfigurado el valor cultural real de la iniciativa. Desde luego, es una oportunidad para la visita y el disfrute del patrimonio histórico, de los museos en general, y de los de perfil pedagógico igualmente, pero hemos de ser muy cuidadosos con las formas y organización de las visitas para procurar que el disfrute estético y la impregnación cultural resulten exitosos.

La historia de los museos nos muestra que se ha producido un cambio profundo de modelo en las formas de consumo y disfrute de ese tipo de patrimonio histórico y cultural, por razones científicas, sin duda, pero también como consecuencia de la emergencia de un nuevo paradigma en las relaciones de intercambio social, como factor económico indudable, como es el turismo de masas, incipiente en los finales del XIx, con alternancia en la primera parte del xx, ya muy afianzado en la segunda mitad del siglo xx, y en la actualidad desbordante y creciendo, siempre que la sociedad que lo propone como recurso de recreo y ocio ofrezca garantías de paz, seguridad y estabilidad. El turismo es un fenómeno de obligada consideración, también para el museísmo pedagógico, cuando éste sea capaz de ofrecer exposiciones, actividades y salas llamativas y de alta calidad en sus instalaciones.

Contemplando otras novedosas vías de orientación socioeducativa que se hacen presentes en el museismo pedagógico actual, nos interesa reflexionar sobre el valor intangible de la socialización y la construcción de vida comunitaria que emerge de la vida de un museo pedagógico, como puede suceder con otras modalidades de museos próximos, el etnográfico por ejemplo. En esta línea se sitúan muchas de las propuestas que se exponen desde el grupo de la Universidad de Vic (Carrillo et al., 20II) sobre la proyección cívica del patrimonio educativo y de los museos pedagógicos en particular.

Un museo pedagógico ubicado en una ciudad, en un barrio, en una determinada comarca rural se erige en una oportunidad para la participación y la gestión cultural 
cooperativa, para afianzar proyectos socioeducativos de carácter solidario y de crecimiento de iniciativas originales y compartidas. Participar de manera constructiva y generosa en una iniciativa cultural pública es una oportunidad para crecer a sus agentes dinámicos y para enriquecer la red de oportunidades socioeducativas, para construir señas de identidad personal y colectiva, de afianzar el valor interno y socializante del grupo promotor. Tal vez el aprovechamiento coordinado de los recursos patrimoniales de la comarca, del barrio, de la ciudad puede representar una mejora en el valor social añadido del esfuerzo humano y material realizado en la puesta en marcha de la iniciativa, del desarrollo comunitario y ciudadano. Es una forma más de construir ciudad educadora, concepto dinámico como pocos, o dinamizar la vida asociativa de una comarca tomando como referente la red de museos, entre ellos, el pedagógico, si llega el caso.

\section{Conclusiones}

Más allá de las modas culturales y coyunturas científicas o políticas, y con independencia de las modalidades de museos pedagógicos que podemos identificar cerca de nosotros, conviene prestar atención sobre el valor social y comunitario que posee el recurso patrimonial representado en un museo pedagógico. Si partimos del sentido de uso social y disfrute colectivo de un establecimiento pedagógico y cultural de esta clase, hemos de contribuir a que arraigue y se consolide como iniciativa bien concebida en lo técnico como establecimiento cultural y pedagógico.

Pero existe otra faceta en el museísmo pedagógico que debe postularse como bandera, y no es otra que su dimensión socioeducativa, su función transformadora y de mejora de las condiciones culturales de la comunidad donde se inserta el museo pedagógico. Por esto, un museo pedagógico alcanzará su sentido pleno si se concibe inserto en una red de recursos patrimoniales y pedagógicos que tome la comunidad, el barrio, la ciudad como sujeto de acción preferente, porque se verá más identificado con el proyecto pedagógico comunitario, y en consecuencia beneficiado y enriquecido culturalmente.

\section{Bibliografía}

Alonso Ponga, José Luis; Díaz González, Joaquín y Piñel Sánchez, Carlos (2006) Teoría $y$ praxis de la museografía etnográfica. Zamora: Museo Etnográfico de Castilla y León.

Álvarez Domínguez, Pablo (coord.) (2016) Los museos pedagógicos en España. Entre la memoria y la creatividad. Gijón: Ediciones Trea.

Carrillo, Isabel; Collelldemont, Eulàlia; Martí, Jordi y Torrens, Jacint (2OII) Los museos pedagógicos y la proyección cívica del patrimonio educativo. Gijón: Ediciones Trea.

Collelldemont Pujadas, Eulalia (20io) Los museos virtuales de educación en España. En Julio Ruiz Berrio (ed.) El patrimonio histórico educativo. Su conservación y estudio. Madrid: Biblioteca Nueva (pp. 275-293).

Fiorani, Eleonora (2002) Gramatica della comunicazione. Milano: Lupetti.

García del Dujo, Ángel (1985) El Museo Pedagógico Nacional y las corrientes pedagógicas contemporáneas. Historia de la Educación, 4, I69-182.

García Fernández, Isabel (ed.) (2015) Museos universitarios. Tradición y futuro. Madrid: Universidad Complutense de Madrid. 
Grassi, Chiara (2015) Il museo tra storia, cultura e didattica. Funzione educativa e ruolo sociale. Pisa: Edizioni ETs.

Hernández Díaz, José María (1993) Las exposiciones pedagógicas y la historia material de la educación. En VII Coloquio de Historia de la Educación. Educación y europeismo. De Vives a Comenio (pp. 321-332). Málaga: Universidad de Málaga.

Hernández Díaz, José María (1997) La etnografía escolar, entre el corazón y la razón. Vela Mayor. Revista de Anaya, II, 43-5I.

Hernández Díaz, José María (2000) Los museos de educación en España. En Rogerio FerNANDes y Margarida Felgueiras (orgs.) A escola primaria: entre a imagem e a memoria (pp. 94-IO4). Porto (Portugal). Projecto Museu Vivo da Escola Primaria.

Hernández Díaz, José María (2003a) Museos pedagógicos y exposiciones educativas en España en los inicios del siglo xxi. En Vicente PeÑa SAavedra (coord.) I Foro Ibérico de museismo pedagógico. O museismo pedagoxico en España y Portugal. Itinerarios, experiencias y perspectivas. Actas, (pp. II7-I80). Santiago de Compostela: Mupega-Conselleria de Educación e Ordenación universitaria da Xunta de Galicia.

Hernández Díaz, José María (2003b) Etnografía e historia material de la escuela. En Agustín Escolano Benito y José María Hernández Díaz (coords.) La memoria y el deseo. Cultura de la escuela y educación deseada, (pp. 227-246). Valencia: Tirant lo Blanch.

Hernández Díaz, José María (2009) José Pedro Varela y el patrimonio escolar en el Museo Pedagógico de Montevideo. Cabás. Revista del Centro de Recursos, Interpretación y Estudios en materia educativa (CRIEME) de la Consejería de Educación del Gobierno de Cantabria (España) (publicación seriada en linea), 7 páginas, número 2, diciembre 2009.

Hernández Díaz, José María (20I0) Los útiles de la cultura escolar y su narrativa en la España contemporánea, Educatio. Siglo XXI, 28, 2, 65-88.

Hernández Díaz, José María (20II) Etnografía escolar e Historia de la Educación. Pistas de aproximación. En Alejandro Mayordomo Perez; M. ${ }^{a}$ Carmen Agulló Díaz y Gabriel GARCía FrASQUET (coords.) El patrimoni histórico educatiu valencià, Gandía: Universitat de Valencia/Alfons el Vell/Ayto. de Gandía, 65-96.

JuAn Borroy, Victor (ed.) (2008) Museos pedagógicos. La memoria recuperada. Huesca: Gobierno de Aragón. Departamento de Educación, Cultura y Deporte. Museo Pedagógico de Aragón.

López-Ocón, Leoncio; Aragón, Santiago y Pedrazuela, Mario (eds.) (20I2) Aulas con memoria. Ciencia, educación y patrimonio en los institutos bistóricos de Madrid (1837-1936). Madrid: Comunidad de Madrid.

Mogarro, María João (coord.) (20I3) Educaçao e patrimonio cultural. Escolas, objetos e práticas. Lisboa: Ed. Colibri.

Moreno, Pedro Luis (2010) Remitimos al monográfico que coordinó sobre «Patrimonio y educación» en Educatio. Siglo XXI, 28, 2.

Peña SaAvedra, Vicente (coord.) (2003) I Foro Ibérico de museísmo pedagógico. O museismo pedagoxico en España y Portugal. Itinerarios, experiencias y perspectivas. Actas, Santiago de Compostela: MUPEGA-Conselleria de Educación e Ordenación universitaria da Xunta de Galicia.

Peña Saavedra, Vicente (dir.); Fernández González, Manuel y Montero Feijoo, Óscar (2004) Os museus da educación en Internet. Santiago de Compostela: Xunta de Galicia.

Ruiz Berrio, Julio (2006) Historia y museología de la educación. Despegue y reconversión de los museos pedagógicos. Historia de la Educación. Salamanca, 25, 271-290.

Ruiz Berrio, Julio (ed.) (20Io) El patrimonio histórico educativo. Su conservación y estudio. Madrid: Biblioteca Nueva.

Sachetтo, Pier Paolo (1986) El objeto informador. Barcelona: Gedisa.

Stocking, G. W (ed.) (1985) Objects and others. Essays on museums and material culture. Madison: University of Wisconsin. 